\title{
PSYCHE.
}

NOTES ON THE ACRIDIDAE OF NEW ENGLAND.-II.-TRYXALINAE. - V.

BY ALBERT P. MORSE, WELLESLEY, MASS.

\section{Orphula Stål.}

Orphuba Stål. I873. Recensio orthopterorum, i, p. 105 .

According to Brunner's Revision the three following species belong to Orphula. Giglio-Tos, however, has separated from Orphula (Boll. Mus. Zool. ed. Anat. comp. R. Univ. Torino, Sept. '94) a group to which he applies the name Orphulella, giving it generic rank, and restricting the former to a single species. To Orphulella apparently belongs our maculipennis, but our other two species present characters intermediate between the two genera as characterized by Giglio-Tos. In consequence of this fact and the very great similarity of our species I am disposed to regard Orphulella as worthy of subgeneric rank only, and have retained the older name in its wider sense for our species.

The species of this genus are among the most difficult to discriminate of any of our locusts. It has been only by a large amount of collecting and observation in the field that I am enabled to present any positive statements regarding the forms described, so variable are individuals of the same species in color, markings and structure. The characteristic differences of each form are given very fully in the key, but individuals vary so much that no specimen can be determined with entire confidence from a single character; yet by taking into consideration all the differences indicated I have had very little difficulty in identifying nearly 2500 specimens, less than half-a-dozen causing even temporary doubt.

We have in New England three distinct species of the genus, and I have no reason to think that there are more, though I have not been able to collect in the extreme.north and northeast. These conclusions are practically the same as were published at the time of the description of olivaceus (Psyche, June, '93). Our species are best known under the names of Stenobothrus maculipennis, aequalis, and olivaceus. Olivaceus, the last species to be described, seems not to have been previously noticed, but the other two are more or less affected by several names applied to representatives of this genus from this region; these are: pelidnus Burm., 
speciosus, bilineatus, and propinquans Scudd. Pelidnus has priority over all; it was described from Penn. and the description agrees most closely with maculipennis, which would in this case become a synonym. Speciosus, maculipennis, aequalis, bilineatus, and propinquans were described next, in the same publication, in the order given, all the descriptions appearing at the same time, speciosus from a single specimen from Minn., the others from several, chiefly from New England. Of these the descriptions of maculipennis and aequalis best characterized the species to which they were applied and in consequence have been most widely used; bilineatus was applied to the brown form of aequalis and has properly been reduced to a synonym or retained in varietal rank merely, to denote this color-form. The type of speciosus also may prove to belong to aequalis in which case this name also will become a synonym. Propinquans was described from Minn. and Conn. and a word concerning it is necessary. In my Preliminary List I have given it as a synonym of pelidnus on $\mathrm{Mr}$. Scudder's authority, based on inspection of the types some years ago. I also stated that from an examination of the types of propinquans I suspected them to be long-winged examples of aequalis. These types have unfortunately been inaccessible to me in the preparation of this paper with the exception of a single specimen from New England which was probably such and which is undoubtedly aequalis. It may be, however, that individuals of both maculipennis and aequalis were included in the types of propinquans. So closely do the species of this genus resemble each other that it would be impossible without an examination of the types of pelidnus and a thorough collection and study of the species from Penn. and Minn, to say which, if any, of these names should be abandoned. Since the species are now wellcharacterized under their present names, it seems the wisest course to retain them rather than change the nomenclature on an uncertainty.

8. Orphula maculipennis Scudd. Figs, 8, 8a, 8b, 8c, 8d, 8e.

Stenobothrus maculipennis. Scudder, 458. 1862. Thomas, 87. Fernald in part, 37. Beutenmüller, 293. Morse, I4, I05; Psyche, '93, p. 478.

I have taken nearly 600 examples of this species but have yet to see one with tegmina failing to reach the end of the hind femora. Brown specimens are more plentiful than green, the relative proportion seeming to be affected by the environment, as in aequalis; green $q$ vary from one-eighth to onethird as common as brown; bright green $\delta$ are very scarce, and discolor somewhat in drying, becoming brownish, so that they appear less plentiful in the collection than in the field. Individuals are sometimes rose-red on the costal and anal parts of the tegmina with the pronotum and head either brown or green, the occiput being 
striped lengthwise or not, and the sides of the pronotum banded or not, exactly as in aequalis; but there seem to be fewer individuals showing intermediate shades of coloring.

\begin{tabular}{|c|c|c|c|}
\hline $\begin{array}{l}\text { Antenna. } \\
\delta^{7} 4 \cdot 7-6.5\end{array}$ & $\begin{array}{l}\text { Hind fem. } \\
8.5-9.8\end{array}$ & $\begin{array}{l}\text { Teg. } \\
\text { 22.5-r } 6.5\end{array}$ & $\begin{array}{c}\text { Teg. }>\text { Hind fem. } \\
I-4.5\end{array}$ \\
\hline \multirow[t]{2}{*}{$5 \cdot 5-7$} & $10.5-12.5$ & $\mathrm{I} 3.5^{-20}$ & $: 5-3$ \\
\hline & $\begin{array}{l}\text { Body. } \\
14.5^{-15.5^{-}} \\
16.5^{-23} \cdot 5\end{array}$ & $\begin{array}{r}\text { To } \\
1.68 \\
\text { I }\end{array}$ & $\begin{array}{l}2 . \\
20.5 \\
26\end{array}$ \\
\hline
\end{tabular}

In the $\delta$ the hind femora usually extend $2 \mathrm{~mm}$. beyond the end of the abdomen, in the $q$ a little less.

This species begins to appear about the middle of July, being a week or two later than aequalis, and may be found during the remainder of the season. The earliest date on which I have taken it is July 18 and the latest Sept. 8. It is an active and alert species, leaping well and also flying freely and well, sometimes for two or three rods. I have found it common along the seashore of the three southern New England States, and in the northeastern part of Conn. It is found on the drier portions of the land adjoining saltmarshes, on the more densely grassed portions of ground just inshore of the sandy beaches, and on sandy or loamy soil further inland.

In Conn. I have taken it at Greenwich, Stamford, North Haven, Deep River, Niantic, Montville, Thompson; in R. I. at Kingston, Wickford, and on Block Id.; in Mass. on Cuttyhunk and Penikese Ids., at West Chop, M. V., Wood's Holl, Provincetown, Revere, and a single $\delta$ and $q$ at Welles- ley. The specimens referred to this species in Smith's Orth. of Maine are longwinged examples of aequalis, as probably are also those spoken of by Scudder in Distribution of insects in $\mathrm{N}$. H. where this species is said to occur in the White MIt. valleys and elsewhere.

9. Orphula aequalis Scudd. Figs. 9, 9a, 9b, 9c.

Stenobothrus aequalis. Scudder, 459 , 1862. Thomas, 89. Beutenmüller 294. Morse, I4, I04; Psyche, '93, p. 478 .

Stenobothrus bilineatus. Scudder, 460. Thomas, 90.

Stenobothrus maculipennis, in part. Fernald, 37. Comstock, Introd., I02. Smith, Orth. Me., I48; Orth. Conn., 376 .

This species is one of our most variable locusts in color and markings, and to a scarcely less extent in structure. The tegmina and wings, while usually about reaching the end of the hind femora, are often considerably shorter, and occasionally extend beyond them. The long-winged specimens occur everywhere but seem to vary in numbers locally, being common in the hilly, elevated districts of Norway, Me., and Adams, Mass., but very scarce in the vicinity of Wellesley. Long-winged females are rather more common than males.

In color the discoidal field of the tegmina is tolerably uniform, being brownish, pellucid distally, more or less maculate with fuscous spots, or even unspotted. The costal (margi- 
nal) and anal areas are very variable and may agree or differ in color with each other or with the top of the head and pronotum. These variations are endless but the more striking ones are the following :

Head. Pronotum. Tegmina.

$\begin{array}{cccc}\text { I } & \text { Green. } & \text { Green. } & \text { Green. } \\ 2 & 66 & 66 & \text { Rose-red. } \\ 3 & \text { Brown } & \text { Brown } & \text { 66 } \\ 4 & 66 & \text { 6 } & \text { Brown. }\end{array}$

The occiput may or may not have a pair of longitudinal fuscous stripes, and the lower half of the side of the pronotum may or may not be crossed by an irregular fuscous band. These variations in color of particular parts occur independently of each other and of wing-length and vary extremely in tint. For instance, the general color of the insect being brown or green the dorsum of the pronotum may be pale gray or dark fuscous. The color of a large series of specimens, however, seems to agree to some extent with that of the environment, whether damp and the vegetation largely greenish, or dry and chiefly brown. Brown females are most plentiful and green males least so, though not uncommon.

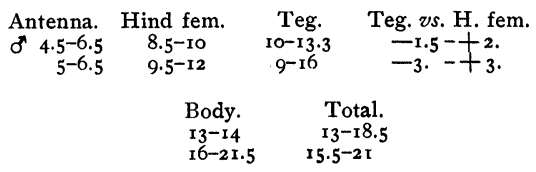

This species makes its appearance the first week in July and probably may be found during the remainder of the season, though becoming scarce in October. It is plentiful by July I 5 and still common at the middle of September. It is one of the most plentiful and widespread of all our locusts but owing to its small size and non-migratory habits does not attract the attention given to the larger and consequently more destructive species. While somewhat local it is found nearly everywhere on dry, sandy or loamy soils, sometimes in company with maculipennis near the coast, and abundantly inland. It moves chiefly by leaping, but readily takes wing on occasion, flying, however, but a few feet. Active and alert in the hot, sunny weather of mid-summer, it can best be secured by sweeping the net rapidly over the ground, a dozen or two of specimens being the result of a few minutes work.

Of this species I have about I5oo specimens mostly of my own collecting, from many localities, among them the following : Deering, Fryeburg, Norway, and Speckled Mt., Me. ; Hanover (Prof. C. M. Weed), No. Conway, Kearsarge Mt. (2000 ft.), and Kingston (S. Wr. Denton), N. H. ; Brattleboro' (Mrs. J. B. Powers), Vt.; Canaan, Stamford, New Haven, Niantic, and Thompson, Conn. ; Kingston and Wickford, R. I. ; Cuttyhunk and Penikese Ids., West Chop, M. V., Wood's Holl, Mt. Hermon and Easthampton (S. W. Denton), Adams, Palmer, Worcester, Belmont (C. J. Maynard), Revere, Blue Hill, and the vicinity of Wellesley. 
The specimens from Speckled Mt., Me. four in number, are all long-winged and perhaps flew there in the adult stage.

Io. Orphula olivacea Morse. Figs. 10, Ioa.

Stenobothrus olivaceus. Morse,Psyche, '93, 477; '94, 104. Beutenmüller, 294 .

This species I have described in full elsewhere (loc. cit.) and there is very little new to add here. The $\delta$, while often presenting a greenish hue at capture, dries to a dull brown. The green form of $q$ is about one-fourth to one-third as numerous as the brown.

In New England it is known only from Greenwich and Stamford, Conn. Beutenmuller reports it from Sandy Hook, N. J., and I have received it from Prof. J. B. Smith, from Anglesea, N. J., where it seems to be common. One female from the latter place is extremely large, measuring as follows : hind fem. I4.5; teg. 22 ; total length $30 \mathrm{~mm}$.

\section{THE CONDITION OF APATELA.}

By A. Radcliffe grote, A. M., hildesheim, Germany.

It is a matter for regret that in 1867 we had no larger series of the American species with us, when the late Mr. C. T. Robinson was my companion in a visit to Guenée at Chateaudun. I had hamamelis and a paler species, besides a few others, and this paler species is what I subsequently named clarescens in American collections. Guenee had his types in little glass boxes, and, after a long study, thought that the pale species might be clarescens, but it differed from his type somewhat. Guenée said that some of his types were sent back to the British Museum, and some named specimens, but many of his types he had with him. Of some of these he furnished me drawings (which I can no longer find) at a later period. There were no Apatelas among these. One was Oligia exesa, which I recog- nized in my collection and which, with the other American species, we may have to refer to Monodes, as they are probably not congeneric with the type of Oligia, the European O. strigilis.

From what M. Guenée told me, it is clear that positive certainty as to the species of Apatela cannot be obtained until the types are examined which are now with M. Oberthür. These types must be compared with the named examples or types in the British Museum, and, above all, with Guenée's probably sufficient, yet somewhat scanty descriptions in this genus. The decision as to these species cannot rest alone on $\mathrm{Mr}$. Butler's comparisons of the named examples in coll. Brit. Mus. From these named examples Butler and Smith refer clarescens as a synonym of hama. melis, leaving my clarescens without a 

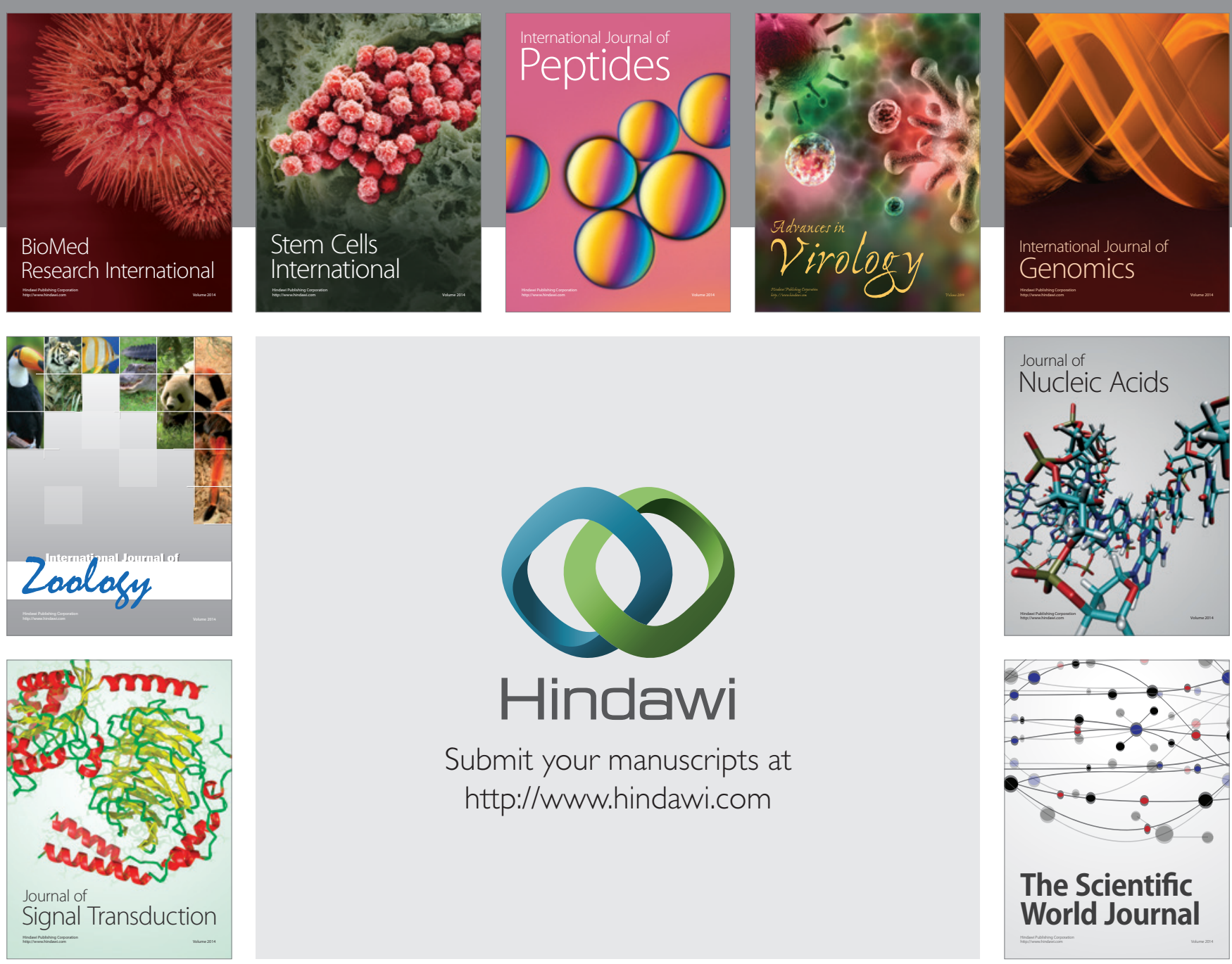

Submit your manuscripts at

http://www.hindawi.com
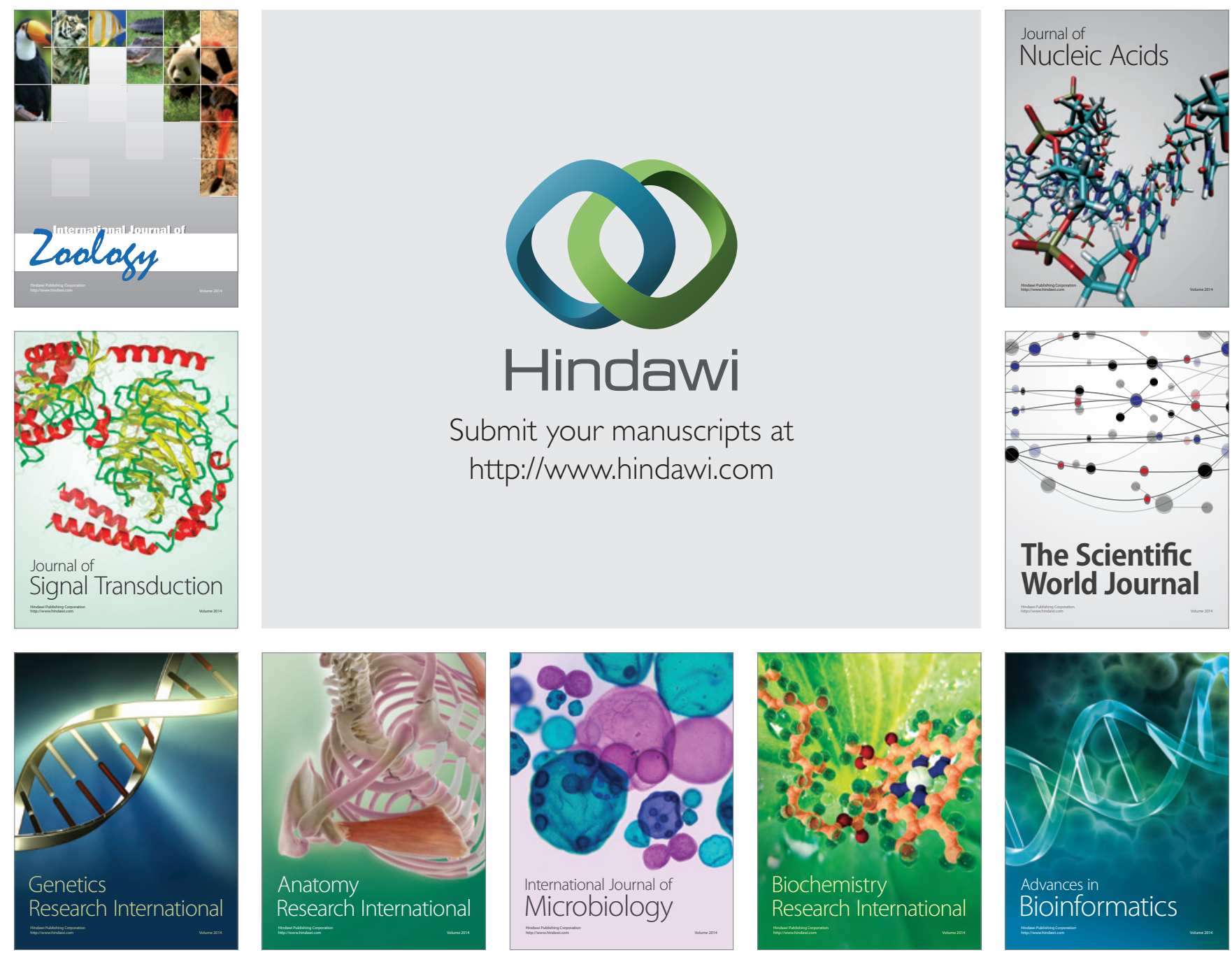

The Scientific World Journal
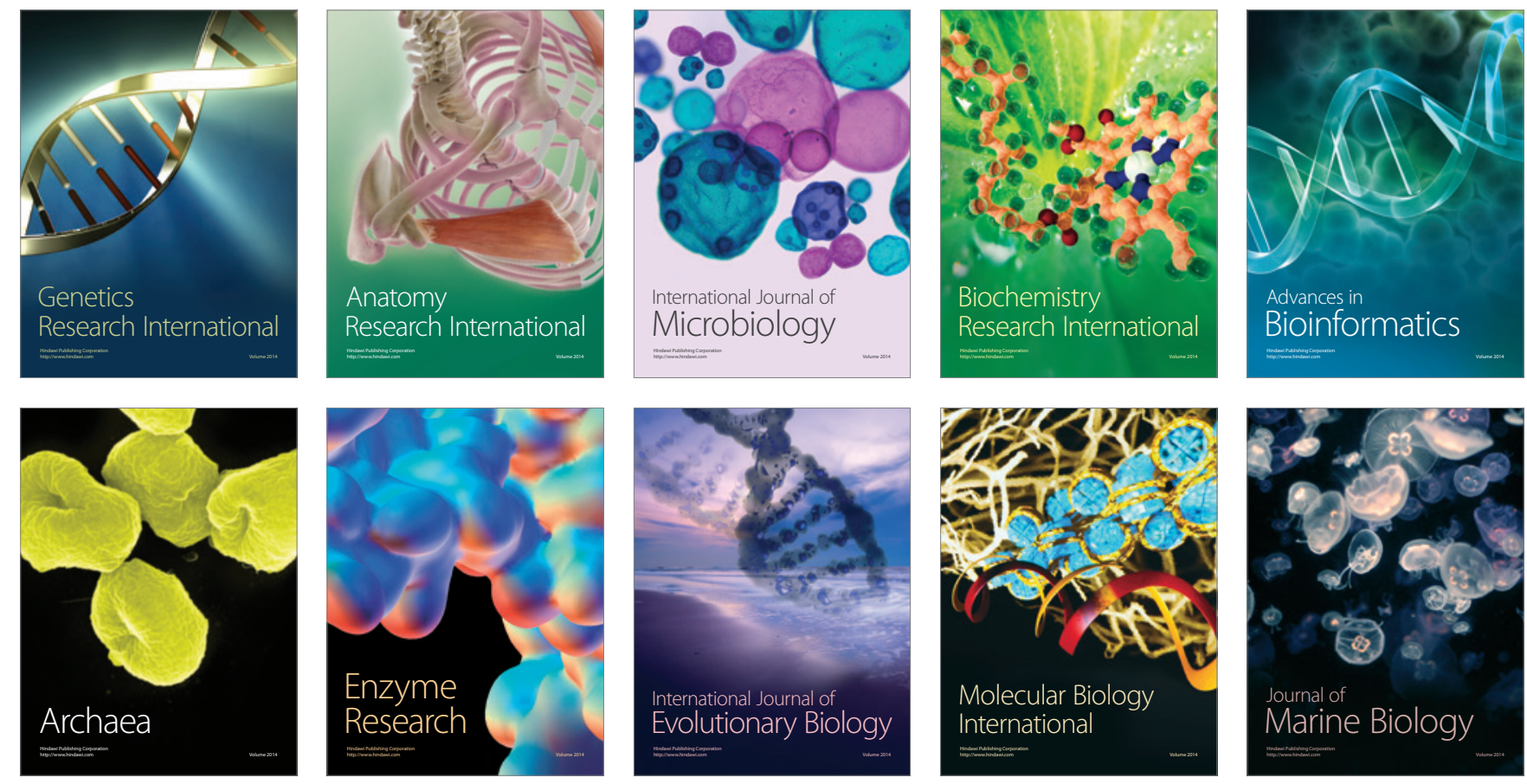